\title{
Liquid-Liquid Phase Separation in Physiology and Pathophysiology of the Nervous System
}

\author{
${ }^{\circledR}$ Yasunori Hayashi, ${ }^{1}$ Lenzie K. Ford, ${ }^{2}{ }^{\circledR}$ Luana Fioriti, ${ }^{3}{ }^{\circledR}$ Leeanne McGurk, ${ }^{4}$ and ${ }^{\circledR}$ Mingjie Zhang ${ }^{5,6}$ \\ ${ }^{1}$ Department of Pharmacology, Kyoto University Graduate School of Medicine, Kyoto 606-8501, Japan, ${ }^{2}$ Zuckerman Mind, Brain, Behavior Institute, \\ Columbia University, New York, New York 10027, ${ }^{3}$ Department of Neuroscience, Mario Negri Institute for Pharmacological Research, Istituto Di \\ Ricovero e Cura a Carattere Scientifico, Milan 20156, Italy, ${ }^{4}$ Cell and Developmental Biology, School of Life Sciences, University of Dundee, Dundee \\ DD1 5EH, United Kingdom, ${ }^{5}$ Division of Life Science, Hong Kong University of Science and Technology, Kowloon, Hong Kong, China, and ${ }^{6}$ School \\ of Life Sciences, Southern University of Science and Technology, Shenzhen 518055, China
}

Molecules within cells are segregated into functional domains to form various organelles. While some of those organelles are delimited by lipid membranes demarcating their constituents, others lack a membrane enclosure. Recently, liquid-liquid phase separation (LLPS) revolutionized our view of how segregation of macromolecules can produce membraneless organelles. While the concept of LLPS has been well studied in the areas of soft matter physics and polymer chemistry, its significance has only recently been recognized in the field of biology. It occurs typically between macromolecules that have multivalent interactions. Interestingly, these features are present in many molecules that exert key functions within neurons. In this review, we cover recent topics of LLPS in different contexts of neuronal physiology and pathology.

Key words: liquid-liquid phase separation; membraneless organelle; local protein synthesis; synapse; neurodegenerative diseases

\section{Introduction}

A neuron has a highly polarized and compartmentalized structure, which requires precise localization of various cellular components. Molecules synthesized in the cell body must travel long distances to reach their final destination. Upon reaching their destination, the molecules must be retained in an appropriate concentration relative to other factors. Additionally, the molecules may need to be segregated from their immediate environment, to establish a functional domain. Anomalies in this process can lead to pathologic outcomes in the brain.

Compartmentalization of molecular processes is accomplished by various intracellular organelles that spatially segregate functionally related molecules. Major organelles, such as the nucleus, endoplasmic reticulum, mitochondria, lysosome, endosome, etc., have demarcating membranes. In contrast, there are organelles that lack any demarcating membrane. These include the nucleoli, chromosomes, ribosomes, centrosomes, RNA granules, and stress granules. How such organelles maintain their constituent molecules was mostly overlooked in early studies using static images. However, a live-imaging study

\footnotetext{
Received June 30, 2020; revised Dec. 17, 2020; accepted Dec. 18, 2020.

This work was supported by Kyoto University SPIRITS 2019, Grant-in-Aid for Scientific Research for Innovative Areas from Ministry of Education, Culture, Sports, Science and Technology, Japan $18 \mathrm{H} 04733$ and 18 H05434 to Y.H., Simons Foundation Award 510178 and Research Grant Council of Hong Kong AoE-M09-12 and C6004-17G to M.Z., Human Frontier Science Program Research Grant RGP0020/2019 to Y.H. and M.Z., Academy of Medical Sciences Springboard Fellowship and University of Dundee start-up grant to L.M., and Telethon Career Award TCP15011 and Alzheimer Association's Grant AARG-17-505136 to Lu.F.

Y.H. was supported by Fujitsu Laboratories and Dwango. The remaining authors declare no competing financial interests.

Correspondence should be addressed to Yasunori Hayashi at yhayashi-tky@umin.ac.jp.

https://doi.org/10.1523/JNEUROSCI.1656-20.2020

Copyright $\odot 2021$ the authors
}

of $\mathrm{P}$ granules, cytosolic protein granules found in germline cells of Caenorhabditis elegans, revealed that these granules have liquid-like properties, including fusion, fission events, changes in size, and reversibility (Brangwynne et al., 2009). At the same time, the molecules undergo constant exchange between the external environment, or dilute phase, and the condensed phase. This exchange was demonstrated by the photobleaching of fluorescently labeled molecules (Brangwynne et al., 2009). These observations required us to rethink how membraneless organelles maintain their shape and constituents.

Subsequently, it was demonstrated that biological macromolecules, including proteins and nucleic acids, can condense and self-assemble into protein droplets in vitro (Kato et al., 2012; Li et al., 2012). Inside the condensate, the molecule can be enriched hundreds of folds compared with the original concentration in the cellular milieu (Zeng et al., 2018). In the simplest scenario, the molecules segregate from the solvent because they can exist more stably in a condensed phase than in a diluted phase, similar to the formation of oil droplets in a water-enriched environment. This phenomenon is called liquid-liquid phase separation (LLPS) because both diluted and condensed phases still retain properties as liquid (Hyman et al., 2014; Banani et al., 2017).

Importantly, the proteins condensed by the mechanism of LLPS still retain native physiological conformation and functions while undergoing exchange between the dilute and condensed phases. This is unlike more solid protein aggregates where the constituent proteins can be misfolded and immobile. However, LLPS can trigger the aggregation of proteins localized to the condensed phase (Hyman et al., 2014; Banani et al., 2017).

LLPS elucidates a wide variety of cellular functions, such as transcriptional and translational regulation, metabolism and catabolism, signal transduction, and cellular motility. It is possible 
that many reported protein-protein interactions mediating these cellular functions are actually part of a larger protein interaction network underlying LLPS. In this review, we discuss the role of LLPS in neurons, with a focus on local protein synthesis, synaptic organization, and neurodegenerative disease.

\section{Biophysics behind LLPS}

LLPS has been well studied in the field of soft-matter physics, but biologists have only recently discovered its importance and implications in divergent cellular functions (Hyman et al., 2014; Banani et al., 2017). The governing mechanism for forming phase-separated condensates in biological systems is multivalent interactions (Li et al., 2012; Banani et al., 2017; Chen et al., 2020). Such interactions can occur between molecules with multiple pairs of specific interactions (e.g., between multidomain scaffold proteins and their binding partners). An increase in multivalency lowers the critical protein concentration required for phase separation ( $\mathrm{Li}$ et al., 2012). Multivalent interactions can also occur among proteins with intrinsically disordered regions, a region of protein without any fixed conformation or domain structure, or with various RNA species. Intrinsically disordered regions are often composed of low-complexity amino acids that are rich in hydrophilic residues (serine, glutamine, glutamate, arginine, and lysine) and that can form electrostatic interactions. Aromatic residues, such as phenylalanine, tyrosine, and tryptophan, are stacked on each other to form $\pi$ electron cloud ( $\pi-\pi$ interaction) or interact with positively charged residues via cation- $\pi$ interactions. In contrast, aliphatic residues, such as valine, leucine, and isoleucine, are less frequently observed in low-complexity domains. Both protein-domain interactions and electrostatic interactions in the intrinsically disordered region contribute to the formation of condensed molecular assemblies with specific and distinct biological functions via phase separation.

In a simple two-molecule system, such as a protein in water, the phase behavior of the solution can be characterized by the free energy diagram (Fig. 1A) and the corresponding phase diagram (Fig. 1B). Under conditions relevant to living cells, most proteins in water form a homogeneous one-phase solution because of the tendency of the mixture to increase its entropy (Fig. 1C). However, on self-interaction, the protein may undergo LLPS, leading to two distinct phases: a highly condensed phase and a dilute phase (Fig. $1 C$ ). In the two-phase mixture, there is no free energy difference between the condensed and the dilute phases. The diffusion chemical potential $(\mu)$ of the protein generated by the concentration gradient between the two phases is offset by the net free energy gain $(\Delta \Delta \mathrm{G})$ of increased binding between protein molecules in the condensed phase because of its higher concentration (i.e., $\mu=\Delta \Delta \mathrm{G}$ ). Thus, the phase-separated liquid solution is at a thermodynamic equilibrium. Nonetheless, protein molecules in the condensed phase can freely exchange with molecules in the dilute phase (Fig. 1D).

The free-energy state of a two-component mixture at any specific condition within the phase separation zone (pale blue and blue regions in Fig. $1 B$; see the corresponding free energy states of the regions in Fig. $1 A$ ) dictates that the system will spontaneously reach to two local minima, corresponding to $\Phi_{\mathrm{d}}$ and $\Phi_{\mathrm{c}}$. Depending on the free energy state, phase separation can occur via binodal nucleation (formation of condensed phase requiring a nucleation processes) or spinodal decomposition (rapid and spontaneous phase separation without nucleation) (Fig. 1E). In a membrane-sealed compartment, exchange of molecules within and outside of the compartment needs to go through the membrane bilayer and requires energy (Fig. 1F). Thus, membraneless organelles are radically different from membrane-based organelles.

Because of the complexity of interactions between biological macromolecules, more than two condensates of different composition can form at the same time in the same cellular compartment. They can form independently of each other (phase-to-phase) or one condensate can form inside of another condensate (phase-inphase) (Kato et al., 2012; Quiroz et al., 2020; Hosokawa et al., 2021). This might account for subdomains observed in some membraneless organelles, such as core-shell architecture of nucleoli, stress granules, and P granules (Kato et al., 2012).

To observe LLPS in vitro, proteins of interest are purified, fluorescently labeled, mixed, and observed by diffusion interference contrast microscopy or fluorescence microscopy (Fig. 1E). Photobleaching of a single fluorescent droplet or part of a fluorescent droplet enables measurements of protein movement within the droplet as well as protein in exchange with diluted phase (Feng et al., 2019). These studies enable researchers to understand how protein components regulate LLPS in vitro; however, it is important to reproduce in vitro studies in the living cell.

\section{LLPS and local protein synthesis}

Membraneless organelles control gene expression, from transcription in the nucleus to local protein synthesis in distal processes (Martin and Ephrussi, 2009; Hnisz et al., 2017; Langdon and Gladfelter, 2018). These organelles circumvent the need for active transport of macromolecules across a membrane, enabling rapid signal transduction. While many of the membraneless organelles involved in gene expression share the biophysical trait of LLPS, each organelle is distinct in its molecular composition and function. Here, we focus on neuronal mRNA-containing ribonucleoprotein (mRNP) granules.

Proteins and mRNAs within neuronal mRNP granules can be dendritically localized (Kiebler and Bassell, 2006), where their translation can be regulated at synapses (Knowles et al., 1996; Kohrmann et al., 1999; Krichevsky and Kosik, 2001; Mallardo et al., 2003; Kanai et al., 2004) (Fig. 2). Retrograde and anterograde transport of these granules is microtubule-dependent (Knowles et al., 1996; Kohrmann et al., 1999). The movement of mRNAs to specific distal sites is necessary for synaptic plasticity and the strengthening of neuronal connections, a critical component of cognitive processes, such as long-term memory (Richter and Lorenz, 2002; Klann and Dever, 2004).

LLPS of components of neuronal mRNP granules plays essential roles in mRNA trafficking and local protein synthesis (Fig. 2). Work from the Kandel and Lu.F. laboratories posits a link between LLPS of cytoplasmic polyadenylation element binding protein 3 (CPEB3) in trafficking dendrite-bound mRNAs that contain cytoplasmic polyadenylation elements (CPEs) (Ford et al., 2019). Indeed, neuronal mRNP granules concentrate a large amount of CPE-containing mRNAs, including CaMKII $\alpha$ (Huang et al., 2003; Martin, 2004). The CPEs promote cytoplasmic polyadenylation-induced translation of the mRNAs in response to synaptic stimulation, such as NMDA-dependent LTP (Gu et al., 1999; Huang et al., 2006; Fioriti et al., 2015). Kandel and Lu.F. have shown that CPEB3 binds CPEs of dendrite-bound mRNAs, providing translational regulation that is necessary for memory persistence (Fioriti et al., 2015). Additionally, they found that CPEB3 undergoes LLPS when bound to its target mRNA and is SUMOylated (Ford et al., 2019), suggesting that LLPS plays a role in translation regulation. Indeed, CPEB3 leaves the 
A

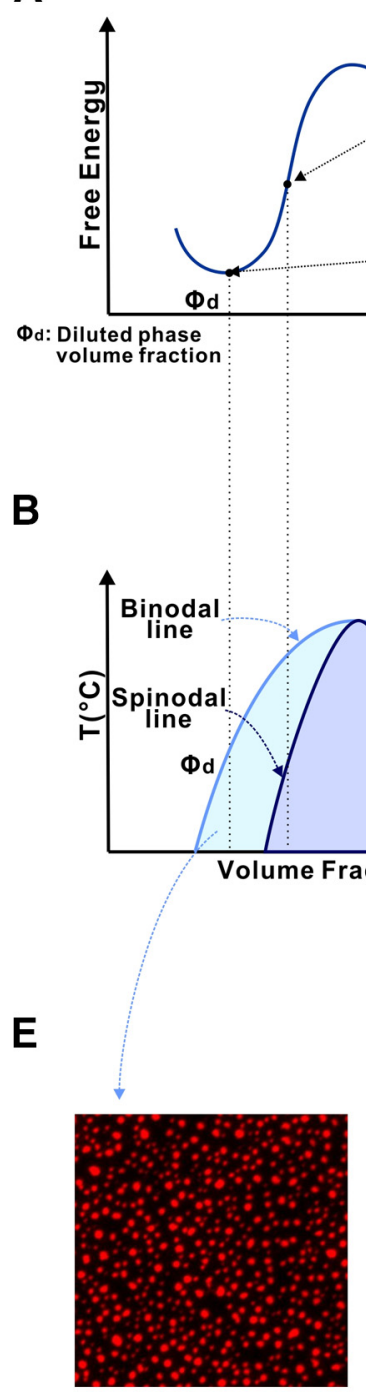

Binodal nucleation

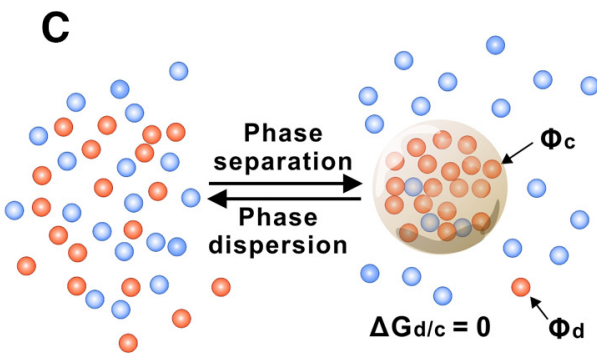

D
$\mathbf{F}$

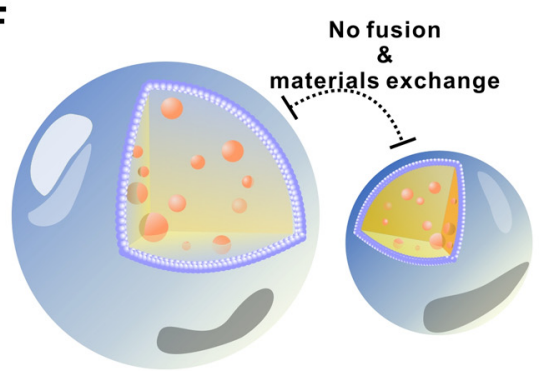

Membrane-enclosed compartments

Figure 1. Phase separation illustrated by a simple two-component system. $A$, Free energy diagram showing phase separation of a two-component system (e.g., a protein indicated by blue dots; in water indicated by brown dots) under a certain condition. A uniformly mixed system can undergo phase separation by lowering the free energy to its minima, which results in a twophase system: a dilute phase ( $\Phi_{\mathrm{d}}$, expressed as fraction volume for the dilute phase) and a condensed phase ( $\Phi_{G}$ fraction volume for the condensed phase). $\boldsymbol{B}$, Phase diagram of the two-component system constructed by plotting the free energy minima as a function of temperature. Blue curve indicates a sharp boundary (or the threshold concentration) of the system transitioning from a homogeneous single-phase state to a two-phase state. Within the phase separation region, two modes of phase separation, binodal nucleation and spinodal decomposition, can occur. C, In a phase-separated two-component system, a thermodynamic equilibrium is reached (i.e., $\Delta G_{d / c}=0$ ). A sharp gradient in the concentration of the blue molecule is established between the two phases. $\boldsymbol{D}$, After phase separation, the components of the condensed phase and the diluted phase can freely exchange. However, there is no net flow of components between the two phases. $\boldsymbol{E}$, An example of binodal nucleation-induced phase separation forming condensed spherical droplets (left) and an example of spinodal decomposition-induced phase separation forming worm-like condensed networks (right). $\boldsymbol{F}$, In sharp contrast to membraneless condensates, spontaneous compartment fusion or materials exchange does not occur in membrane-separated organelles.

membraneless Processing Body (P body) to join the distally located polysome after chemically induced LTP (Ford et al., 2019). This work identifies the movement of phase separated, translation-dependent components from a repressed state in neuronal mRNP granule-like P bodies (Barbee et al., 2006) to an active state at distal ribosomes, and suggests that $\mathrm{P}$ bodies are playing an essential role in this process (Cougot et al., 2008; Ford et al., 2019).

Fragile X Mental Retardation Protein (FMRP) is another well-characterized component of neuronal mRNP granules, largely studied for its role in the pathogenesis of fragile X syndrome, the most commonly inherited form of mental retardation
(Jin and Warren, 2003). Disruption of FMRP results in altered neural morphology in the form of excessively long and thin filopodia-like spines and fewer mature spines (Nimchinsky et al., 2001). FMRP is localized to the synapse on metabotropic glutamate receptor activation, where it functions to target dendritic mRNAs and regulates translation (Jin and Warren, 2003; Antar et al., 2004). FMRP represses mRNA translation both in vivo and in vitro, possibly by blocking ribosome elongation at the polysome (Zalfa et al., 2006) and/or by miRNA-FMRP interaction, which would repress translation via the RNAinduced silencing complex (Zalfa et al., 2006). Experiments conducted in vitro using reticulocytes extracts and recombinant 


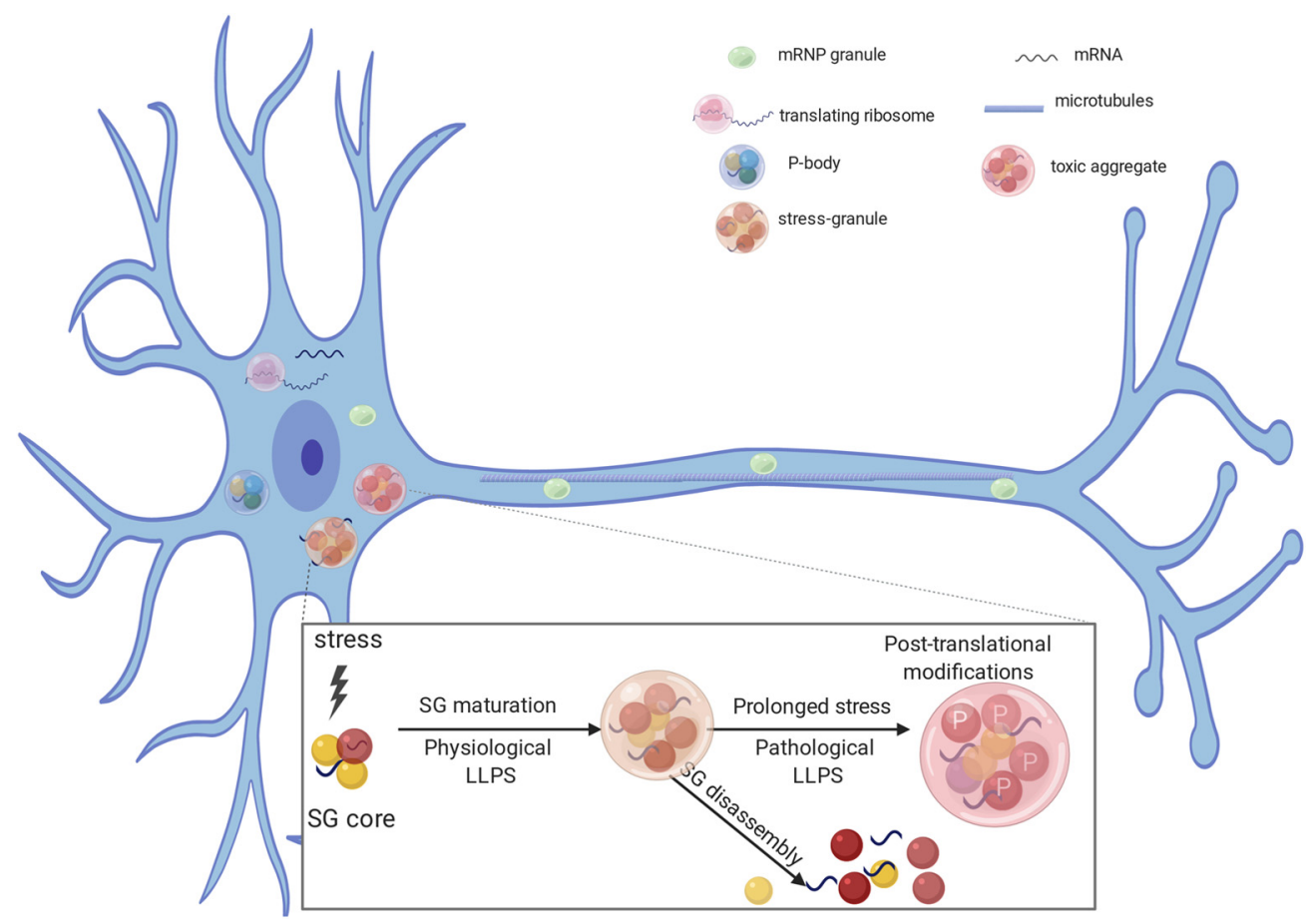

Figure 2. RNA binding proteins are involved in RNA stability ( $P$ bodies), mRNA transport (mRNA transport granules), translation, and stress granules (SG) formation. Under transient stress, protein-protein and RNA interactions form a dense SG core. Several RNA binding proteins can be recruited to SG cores and undergo LLPS forming functional dynamic structures (physiological LLPS). Under conditions of transient stress, SGs are transiently formed but disassemble after the stress is gone. In case of prolonged stress, and after post-translational modifications, such as phosphorylation, proteins can become insoluble (pathologic LLPS). The same RNA binding proteins can participate in the formation of nontoxic hydrophobic aggregates and toxic cytoplasmic inclusions.

FMRP suggest that this translation repression likely occurs within the LLPS state, since FMRP-containing droplets can recruit translational repressors and miRNA (Tsang et al., 2019). However, the same authors do not show direct evidence that only the phase-separated state is capable of repressing translation in an intact cellular environment. Thus, additional studies are necessary to clarify whether the ability to repress translation is an exclusive property of the condensed phase. Interestingly, FMRP LLPS is mediated by binding to its mRNA targets and by post-translational modifications, such as phosphorylation (Tsang et al., 2019). Tsang et al. (2019) predict that additional RNA-binding proteins involved in translational repression might undergo LLPS to function as translational repressors in neurons.

mRNAs in neuronal mRNP granules can also drive LLPS and direct dendritic targeting of mRNP granules. RNA modifies the LLPS behavior of RNA-binding proteins (Maharana et al., 2018); and the post-transcriptional state of the RNA, such as secondary structure, also plays a role in changing LLPS behavior (Langdon and Gladfelter, 2018; Van Treeck and Parker, 2018). Recently, the Jaffery laboratory identified a facilitating role of methylation of adenosine at the nitrogen-6 position (m6A) in LLPS in vitro, and linked the high abundance of m6A RNA to LLPS of specific membraneless organelles (Ries et al., 2019). Interestingly, transcripts critical for synaptic organization and function are highly modified with m6A and are translocated to synapse (Merkurjev et al., 2018). Like the disrupted neuromorphology seen with FMRP mutations (Nimchinsky et al., 2001; Tsang et al., 2019), reducing the levels of the protein "m6A reader," a protein that interacts with m6Amodified mRNA, caused structural and functional deficits in hippocampal dendritic spines (Merkurjev et al., 2018).
Local translation also takes place in axons (Jung et al., 2012; Wong et al., 2017; Hafner et al., 2019). Similarly to the local protein synthesis in dendrites, RNA-binding proteins play a major role in regulating axonal local translation (Antar et al., 2004; Kiebler and Bassell, 2006). A coculture system of Aplysia sensory presynaptic and motor postsynaptic neurons has been used for studies of axonal local translation. After stimulation to induce long-term facilitation, relevant mRNAs, such as sensorin, rapidly concentrate in the presynaptic terminus of sensory neurons (Lyles et al., 2006). Moreover, live-cell imaging of fluorescent translational reporters revealed accumulation of newly synthesized proteins in the presynaptic terminus (Wang et al., 2009), suggesting that local translation occurs in the presynaptic terminus during long-term facilitation.

As they are transported along axons to growth cones or presynaptic structures, RNA-binding proteins and mRNAs form mRNP granules through LLPS. Translation is suppressed in these granules until they receive extracellular signals that initiate local translation. FMRP, together with proteins, such as fragile $\mathrm{X}$ related 1 (FXR1) and FXR2, forms FMRP-containing granules (FXGs) by LLPS, which plays an important role in the translation control (Antar et al., 2006; Li et al., 2009; Till et al., 2011; Parvin et al., 2019; Tsang et al., 2019). These granules are often localized near synaptic vesicles (Christie et al., 2009), which may serve as platforms for local translation at presynaptic structures. The synaptic vesicle protein synapsin 1 condenses into liquid droplets and promotes clustering of synaptic vesicles at presynaptic terminals (Milovanovic et al., 2018). Because FXGs localize with synaptic vesicles, it is possible that FMRP suppresses local translation to maintain mRNAs and translational machinery at the synapsin/synaptic vesicle condensate. Once a signal to initiate 
translation for synapse formation or plasticity is received, FMRP is dephosphorylated and FXGs are dispersed to initiate translation. The surrounding phase environment (synapsin/synaptic vesicles condensate) may affect the process of forming/dispersing FXGs by LLPS. However, further studies at higher resolution are necessary to detect translating ribosomes and FXGs in presynaptic structures in response to extracellular signals.

In summary, a multitude of nuclear and cytoplasmic membraneless organelles play critical roles in gene expression and local protein synthesis. The dense nature of these organelles, with high concentrations of select protein and RNA components, allow for "packets of information" to be delivered directly to relevant active sites. This allows for the efficient, and spatially dependent, production of transcription and translation products in the polarized neuron.

\section{LLPS at the synapse}

Synaptic proteins are continuously turning over (Kuriu et al., 2006; Sharma et al., 2006) and yet synapses can persist for weeks, months, or even the lifetime of the animal (Grutzendler et al., 2002; Yang et al., 2009; Isshiki et al., 2014). A presynaptic terminus shows specific accumulation of component proteins, which tether the synaptic vesicles at rest and, on the influx of $\mathrm{Ca}^{2+}$, fuse them with a specialized part of the presynaptic membrane called the active zone. Postsynaptic receptors are embedded in the plasma membrane, beneath which, various cellular components involved in signal transduction and regulation are enriched and comprise the postsynaptic density (PSD) (Sheng and Hoogenraad, 2007). These presynaptic and postsynaptic structures lack any demarcating membranes that prevent the diffusion of the component molecules into the cytoplasm. Indeed, these properties of protein accumulation are consistent with the phenomenon of LLPS (Fig. 3).

Synapsin is a presynaptic protein that crosslinks synaptic vesicles and tethers them to the cytoskeleton within the resting presynaptic terminus. Upon $\mathrm{Ca}^{2+}$ entry, activated CaMKII phosphorylates synapsin. This reduces the interaction of synapsin with synaptic vesicles and the cytoskeleton, and facilitates the process of vesicular release. When purified, synapsin can undergo LLPS in vitro in a manner recapitulating its in vivo properties (Milovanovic et al., 2018). Synapsin condensates can capture liposomes and are dispersed by CaMKII phosphorylation (Milovanovic et al., 2018). From these observations, synapsin is proposed to cluster synaptic vesicles in the presynaptic terminus by a LLPS-mediated mechanism.

The clustering of membrane surface proteins can also be regulated by LLPS of proteins that bind to intracellular regions of membrane proteins. $\mathrm{Ca}^{2+}$ comes into the presynaptic terminus through voltage-gated $\mathrm{Ca}^{2+}$ channels at the active zone of the presynaptic membrane. The clustering of the voltage-gated $\mathrm{Ca}^{2+}$ channels is mediated by two active zone proteins, Rab3-interacting molecule (RIM) and RIM-Binding Protein (RIM-BP), which interact with voltage-gated $\mathrm{Ca}^{2+}$ channels. RIM has a prolinerich domain and a PDZ domain, which interact with three $\mathrm{SH} 3$ domains in RIM-BP and with the PDZ binding motif of the Ntype voltage-gated $\mathrm{Ca}^{2+}$ channels, respectively (Wu et al., 2019; $\mathrm{Wu}, 2020)$. Through these multiple domain interactions, RIM, RIM-BP, and voltage-gated $\mathrm{Ca}^{2+}$ channels can phase separate and form clusters at the active zone (Wu et al., 2019). Wu et al. (2020) demonstrated that purified synaptic vesicles coat the surface of the RIM/RIM-BP condensates either in solution or tethered to membrane bilayers by the cytoplasmic tail of voltage-gated $\mathrm{Ca}^{2+}$ channels, forming a new type of interaction between a membrane organelle and membraneless organelle. The coating of synaptic vesicles on the surface of active zone condensates implies that the total number of synaptic vesicles tethered to each active zone is determined by its surface area (Schikorski and Stevens, 1997). Remarkably, when the synapsin/vesicle condensates mixed with the vesicle-coated RIM/RIM-BP condensates, the vesicle-coated RIM/RIM-BP condensates are encapsulated by synapsin/ small unilamellar vesicle condensates, forming two distinct small unilamellar vesicle pools reminiscent of the reserve and tethered synaptic vesicle pools existing in presynaptic boutons. Thus, the authors have reconstituted a presynaptic bouton-like structure containing vesicle-coated active zone with one side attached to the presynaptic membrane and the other side connected to the synapsin-clustered synaptic vesicle condensates.

Purified postsynaptic scaffolding proteins Shank and Homer self-assemble into macromolecular complexes when they are mixed together in vitro. Both Shank and Homer are multimeric proteins, and Homer has Enabled/Vasp Homology domain that interacts with Shank (Hayashi et al., 2009). Through this multimer-multimer interaction, the protein complex takes on a highorder meshwork structure and is the proposed underlying framework of the PSD at the excitatory synapse (Hayashi et al., 2009). Similarly, SynGAP, a postsynaptic Ras-activating protein, is a trimeric protein with a PDZ binding motif (Zeng et al., 2016). PSD-95, a postsynaptic scaffolding protein, multimerizes in vitro (Hsueh and Sheng, 1999; Zeng et al., 2018). When purified SynGAP and PSD-95 are combined, they form a macromolecular complex. Interestingly, the resultant complex has droplet-like structures (Zeng et al., 2016). The properties of these droplets, such as spontaneous formation, constant exchange between condensed and diluted phase, and spontaneous fusion, are consistent with the idea that these droplets are formed by LLPS. The phase separation of the PSD-95 and SynGAP mixture also suggests that the dense PSD assemblies beneath, but not enclosed by the postsynaptic plasma membranes, are formed via LLPS. A mutant 
that abolishes LLPS in vitro significantly impaired the enrichment of these proteins in neurons (Hayashi et al., 2009; Zeng et al., 2016).

When additional components of the PSD, including the NMDAR subunit GluN2B (which has a PDZ binding motif), GKAP (which bridges PSD-95 and Shank), Shank, and Homer were added to a PSD-95/SynGAP mixture, this resulted in LLPS at lower protein concentration, indicating a synergetic effect on the phase formation (Zeng et al., 2018; Chen et al., 2020; Wu, 2020). However, the contribution of each protein to phase separate is different. Removal of PSD-95 significantly reduced GluN2B but not Shank and Homer. In contrast, removal of Shank significantly reduced Homer but had less impact on PSD-95 and SynGAP. This suggests that some proteins serve as a "driver" for the formation of phase separation, whereas others serve as a "client." PSD-95 serves as a major driver of phase separation, whereas GluN2B serves as a client. In contrast, Homer and Shank form an independent layer that does not serve as a driver or client for PSD-95/SynGAP/GluN2B. This is consistent with electron microscopic observations of the laminal structure of PSD (Valtschanoff and Weinberg, 2001), where PSD-95 and GluN2B are layered together immediately beneath the synaptic membrane, while Shank is in a deeper layer. GKAP is an interesting molecule in this structure: when it was removed, both PSD-95/SynGAP/GluN2B and Shank/Homer had significantly reduced phase formation. GKAP is situated between these two layers in the protein complex and may serve as an interface. Indeed, in native PSDs, GKAP is layered between PSD-95/GluN2B and Shank (Valtschanoff and Weinberg, 2001).

AMPA-type glutamate receptors (AMPAR) are another major receptor group of the excitatory synapse. They interact with a myriad of proteins that regulate the synthesis, function, and subcellular distribution of AMPAR. Major interactors include the transmembrane AMPAR-interacting proteins, which interact with the transmembrane domain of AMPARs and determine receptor localization and function (Nicoll et al., 2006). A prototypical transmembrane AMPAR-interacting protein, Stargazin, can interact with PSD-95 through a PDZbinding motif, as well as through an arginine-rich motif (Zeng et al., 2019). Through such multivalent interactions, Stargazin undergoes LLPS with PSD-95. This is required for efficient incorporation of AMPAR into the synapse.

The induction of synaptic plasticity can persistently alter the amount of the AMPAR and various other proteins residing at the synapse (Bosch et al., 2014). Thus, an important and outstanding question is how neuronal activity modulates postsynaptic LLPS to trigger the delivery of synaptic proteins. The induction of LTP induces a delivery of postsynaptic proteins in a specific order from the dendritic shaft. Actin and actinrelated proteins are the first to arrive at the synapse, followed by AMPAR. PSD scaffolding proteins, such as PSD-95 and Homer, take longer to increase $(\sim 2 \mathrm{~h})$ after LTP induction, and require the synthesis of new protein (Bosch et al., 2014). In contrast, SynGAP, another PSD protein that inhibits Ras activity, dissociates quickly from the synapse on phosphorylation by CaMKII (Araki et al., 2015). Furthermore, phosphorylation of Stargazin by CaMKII negatively affects LLPS (Zeng et al., 2019). Because activation of CaMKII transiently occurs after LTP induction (Lee et al., 2009), this might create a time window for reorganization of the postsynaptic protein condensate.

Indeed, CaMKII has several properties that enable it to undergo LLPS. Once activated by $\mathrm{Ca}^{2+} /$ calmodulin, CaMKII can form a persistent complex with substrate proteins, including the intracellular carboxyl tail of the NMDAR subunit GluN2B, Rac guanine nucleotide exchange factor Tiam1, GJD2/connexin 36, LRRC7/densin-180, and the L-type $\mathrm{Ca}^{2+}$ channel. In addition, CaMKII has a rotationally symmetric dodecameric structure that can simultaneously interact with these proteins and cross link them. The ability of CaMKII to undergo LLPS was experimentally demonstrated by using purified CaMKII and other PSD proteins, including the scaffolding protein PSD-95, GluN2B, and Stargazin as a proxy of AMPAR itself. Notably, CaMKII undergoes phase separation with these proteins only in the presence of $\mathrm{Ca}^{2+}$; and after it undergoes LLPS, this state persists even after chelation of $\mathrm{Ca}^{2+}$. This persistence of LLPS after $\mathrm{Ca}^{2+}$ chelation requires phosphorylation of threonine 286 of CaMKII, which has been shown to render CaMKII constitutively active. Therefore, one major role of CaMKII at the synapse may be to link different postsynaptic molecules through LLPS in a manner triggered by $\mathrm{Ca}^{2+}$ (Hosokawa et al., 2021).

In a related study, Cai et al. (2020) discovered that autoinhibited CaMKII $\alpha$ specifically binds to Shank3. In a reconstitution buffer containing no $\mathrm{Ca}^{2+}$, mixing CaMKII $\alpha$ and Shank3 leads to phase separation of the mixture. Addition of $\mathrm{Ca}^{2+}$ induces GluN2B-mediated recruitment of active CaMKII $\alpha$ and formation of the GluN2B/ PSD-95/CaMKII $\alpha$ condensates, which is autonomously dispersed on $\mathrm{Ca}^{2+}$ removal. Protein phosphatases control the $\mathrm{Ca}^{2+}$-dependent shuttling of CaMKII $\alpha$ between the two PSD subcompartments (the upper layer composed of GluN2B/PSD-95 and the lower layer composed of GKAP/Shank3/Homer). Activation of CaMKII $\alpha$ further enlarges the PSD assembly, mimicking activity-induced structural LTP in synapse. Therefore, $\mathrm{Ca}^{2+}$-driven and phosphatase-checked shuttling of CaMKII $\alpha$ between distinct PSD nanodomains may underlie structural plasticity of PSD assemblies via LLPS (Cai et al., 2020).

LLPS of CaMKII is also involved in the segregation of synaptic surface proteins. Glutamate receptor subtypes are organized into nanodomains at the synapse. In each hippocampal synapse, NMDAR forms one dominant nanodomain and several small domains, whereas AMPAR segregates into several nanodomains of similar size surrounding the NMDAR. In contrast, metabotropic glutamate receptors are more diffuse (Goncalves et al., 2020). Postsynaptic nanodomains connect to the presynaptic active zone via cell adhesion molecules, thereby forming transsynaptic nanocolumns (Tang et al., 2016; Biederer et al., 2017; Scheefhals and MacGillavry, 2018). CaMKII preferentially interacts with the NMDAR subunit GluN2B rather than the AMPAR, represented by Stargazin. This leads to the formation of a phasein-phase structure of AMPARs within the NMDAR-CaMKII phase. Further, the cell-adhesion molecule neuroligin segregates with the AMPAR and connects the presynaptic neurexin with the presynaptic release machinery. This mechanism may place AMPARs just beneath the transmitter release site, thereby optimizing the transmission efficacy and serving as a novel mechanism CaMKII-mediated synaptic plasticity.

In contrast to prominent PSD assemblies in excitatory synapses, inhibitory synapses do not contain obvious dense thickening underneath synaptic membranes. However, recent cryo-EM tomography studies reveal a sheet-like dense assembly (referred to as iPSD) with a thickness of $\sim 5 \mathrm{~nm}$ (Tao et al., 2018). A recent study has demonstrated that glycine or $\mathrm{GABA}_{\mathrm{A}}$ receptors, together with gephyrin, a key scaffold protein in inhibitory synapses, can undergo phase separation, forming iPSD condensates. The formation of the iPSD condensates can be regulated by phosphorylation of gephyrin or binding of 
target proteins to gephyrin (Bai et al., 2020). Thus, analogous to excitatory PSDs, iPSDs are likely formed by phase separation-mediated condensation of scaffold protein/neurotransmitter receptor complexes.

\section{LLPS in neurodegenerative disease}

Neurodegenerative diseases, such as Alzheimer's disease and Parkinson's disease, are currently incurable and have no effective treatments. To identify potential treatments, it is paramount to understand the cellular and pathologic basis of disease. One defining cellular feature of neurodegenerative disease is the deposition of protein aggregates in affected brain regions. Protein aggregates in a given disease are formed by a specific protein, for example, the microtube-associated protein tau in Alzheimer's disease and $50 \%$ of patients with frontotemporal degeneration (Mackenzie and Neumann, 2016; Vogels et al., 2020); $\alpha$-synuclein in Parkinson's disease and Lewy body dementia (Luna and Luk, 2015; Zbinden et al., 2020); and TDP43 in $>95 \%$ of patients with amyotrophic lateral sclerosis (ALS) and in $\sim 45 \%$ of patients with frontotemporal degeneration (Mackenzie and Neumann, 2016; Taylor et al., 2016). Microtube-associated protein tau, $\alpha$-synuclein, and TDP-43 have an inherent capacity to aggregate; they harbor diseasecausing mutations, and the anatomic burden of these protein aggregates correlates with symptomatic decline (Luna and Luk, 2015; Mackenzie and Neumann, 2016; Taylor et al., 2016; Harrison and Shorter, 2017; Vogels et al., 2020; Zbinden et al., 2020). How protein aggregates correlate with disease is unclear, but it is emerging that LLPS may be involved. Here we focus on the role of LLPS in ALS.

ALS is an incurable motor neuron disease that leads to paralysis and death within 2-5 years of symptomatic onset (Taylor et al., 2016). In $>95 \%$ of ALS patients, TDP-43 forms phosphorylated protein aggregates in the cytoplasm of affected motor neurons (Arai et al., 2006; Neumann et al., 2006). Mutations in several ALS-linked genes have been identified, and these give rise to $\sim 15 \%$ of ALS cases (Taylor et al., 2016). Many of the mutated genes, including TDP-43, FUS, and TIA1, are RNA-binding proteins that harbor a prion-like domain (Sreedharan et al., 2008; Kwiatkowski et al., 2009; Vance et al., 2009; Kim et al., 2013; Mackenzie et al., 2017). The prion-like domain is an intrinsically disordered region that can promote protein aggregation and protein phase separation both in vitro and in the cell (Johnson et al., 2009; Sun et al., 2011; Han et al., 2012; Kato et al., 2012; Lin et al., 2015; Molliex et al., 2015; Murakami et al., 2015; Patel et al., 2015; Xiang et al., 2015; Conicella et al., 2016, 2020; McGurk et al., 2018a,b; Ryan et al., 2018; Murthy et al., 2019); and it is often the site of disease-causing mutations (Sreedharan et al., 2008; Kwiatkowski et al., 2009; Vance et al., 2009; Kim et al., 2013; Mackenzie et al., 2017). Thus, LLPS is a focus in the underlying pathogenesis of ALS.

In ALS, neurons are under constitutive stress that can arise from misfolded proteins in the endoplasmic reticulum and mitochondrial dysfunction (Kiskinis et al., 2014; Montibeller and de Belleroche, 2018). As a survival mechanism during stress, the cell inhibits global protein translation by sequestering RNA-protein complexes involved in the pre-initiation of protein synthesis into stress granules (Ivanov et al., 2019; Jaud et al., 2020). TDP-43 and several of the RNA-binding proteins linked to ALS localize to stress granules (Bosco et al., 2010; Dewey et al., 2011; Mackenzie et al., 2017; Fernandes et al., 2018). The hypothesis that stress granules are linked to ALS is further supported by evidence that demonstrates that disease-causing mutations in the
RNA-binding proteins linked to ALS alter LLPS in vitro and localization of the respective proteins to stress granules (Lin et al., 2015, 2016; Molliex et al., 2015; Murakami et al., 2015; Patel et al., 2015; Conicella et al., 2016; Lee et al., 2016; Boeynaems et al., 2017; Dao et al., 2018; Wang et al., 2018; McGurk et al., $2018 \mathrm{~b}$ ); that downregulation of pathways that promote stress granule formation mitigate TDP-43-associated toxicity and/or aggregation in various cellular and animal models (Elden et al., 2010; Kim et al., 2014; Becker et al., 2017; Zhang et al., 2018; McGurk et al., 2018c; Duan et al., 2019; Fernandes et al., 2020); and that stress-granule resident proteins coaggregate with $\sim 30 \%$ of TDP-43 inclusions in human ALS tissue (Liu-Yesucevitz et al., 2010; Bentmann et al., 2012; McGurk et al., 2014).

An overarching hypothesis has been that stress-granule localization of TDP-43 seeds the protein aggregation observed in ALS. Stress granules and LLPS condensates are highly concentrated sources of protein, which is a biophysical property that promotes LLPS. Thus, by increasing local protein concentration, LLPS provides an environment that can promote phase transition events that lead to the formation of protein oligomers with solid-like characteristics (Kato et al., 2012; Molliex et al., 2015; Murakami et al., 2015; Patel et al., 2015; Guo et al., 2018). In in vitro experiments, solid protein oligomerization within protein condensates can also be promoted by increasing the time the proteins are in the protein droplet, by repeated forming and dissolving the protein droplets, and by introducing disease-associated mutations to the protein (Lin et al., 2015; Molliex et al., 2015; Patel et al., 2015). In line with these in vitro data, cells exposed to chronic stress form stress granules and persistent TDP-43 aggregates (McGurk et al., 2018b; Gasset-Rosa et al., 2019; Fernandes et al., 2020), suggesting that chronic stress and/ or stress-granule localization leads to disease-like aggregation of TDP-43. However, under short-term stress, stress granules inhibit the formation of disease-like aggregates of TDP-43 and promote the solubility and dissolution of the protein after the removal of stress (McGurk et al., 2018b; Chen and Cohen, 2019; Gasset-Rosa et al., 2019; Mann et al., 2019; Fernandes et al., 2020). Thus, under short-term stress, the cell controls both the accumulation and dissolution of TDP-43 aggregates, but under continued stress and maintenance of a condensed phase, TDP43 transitions into disease-like aggregates.

Elucidation of the LLPS-associated dynamics of membraneless organelles and disease-causing proteins may explain the pathology observed in ALS and other neurodegenerative diseases. However, whether protein aggregation causes dysfunction and clinical symptoms is unknown. Data from animal models suggest that targeting pathways that promote LLPS and stress granule biogenesis is therapeutic (Elden et al., 2010; Kim et al., 2014; Becker et al., 2017; Guo et al., 2018; McGurk et al., 2018c; Zhang et al., 2018; Duan et al., 2019; Fernandes et al., 2020). Thus, studying the mechanisms of LLPS is directing us toward pathways with therapeutic potential for incurable diseases, such as ALS.

\section{Concluding remarks}

In conclusion, LLPS is emerging as a key biological phenomenon that mediates several aspects of the basic organization and proper functions of cells in general, and neurons in particular. It will be interesting to see where the field of LLPS will take us in the next few years. We anticipate that combined the technological advancements in super-resolution microscopy and other imaging techniques, we will be able to fill the gaps between in vitro studies and in vivo conditions. Further advancements in our understanding of this phenomenon will also allow us to design new therapeutic approaches against neurodegenerative diseases. 


\section{References}

Antar LN, Afroz R, Dictenberg JB, Carroll RC, Bassell GJ (2004) Metabotropic glutamate receptor activation regulates fragile $\mathrm{X}$ mental retardation protein and FMR1 mRNA localization differentially in dendrites and at synapses. J Neurosci 24:2648-2655.

Antar LN, Li C, Zhang H, Carroll RC, Bassell GJ (2006) Local functions for FMRP in axon growth cone motility and activity-dependent regulation of filopodia and spine synapses. Mol Cell Neurosci 32:37-48.

Arai T, Hasegawa M, Akiyama H, Ikeda K, Nonaka T, Mori H, Mann D, Tsuchiya K, Yoshida M, Hashizume Y, Oda T (2006) TDP-43 is a component of ubiquitin-positive tau-negative inclusions in frontotemporal lobar degeneration and amyotrophic lateral sclerosis. Biochem Biophys Res Commun 351:602-611.

Araki Y, Zeng M, Zhang M, Huganir RL (2015) Rapid dispersion of SynGAP from synaptic spines triggers AMPA receptor insertion and spine enlargement during LTP. Neuron 85:173-189.

Bai G, Wang Y, Zhang M (2020) Gephyrin-mediated formation of inhibitory postsynaptic density sheet via phase separation. Cell Res Advance online publication. Retrieved Nov 2, 2020. doi: 10.1038/s41422-020-00433-1.

Banani SF, Lee HO, Hyman AA, Rosen MK (2017) Biomolecular condensates: organizers of cellular biochemistry. Nat Rev Mol Cell Biol 18:285298.

Barbee SA, Estes PS, Cziko AM, Hillebrand J, Luedeman RA, Coller JM, Johnson N, Howlett IC, Geng C, Ueda R, Brand AH, Newbury SF, Wilhelm JE, Levine RB, Nakamura A, Parker R, Ramaswami M (2006) Staufen- and FMRP-containing neuronal RNPs are structurally and functionally related to somatic $P$ bodies. Neuron 52:997-1009.

Becker LA, Huang B, Bieri G, Ma R, Knowles DA, Jafar-Nejad P, Messing J, Kim HJ, Soriano A, Auburger G, Pulst SM, Taylor JP, Rigo F, Gitler AD (2017) Therapeutic reduction of ataxin-2 extends lifespan and reduces pathology in TDP-43 mice. Nature 544:367-371.

Bentmann E, Neumann M, Tahirovic S, Rodde R, Dormann D, Haass C (2012) Requirements for stress granule recruitment of fused in sarcoma (FUS) and TAR DNA-binding protein of $43 \mathrm{kDa}$ (TDP-43). J Biol Chem 287:23079-23094.

Biederer T, Kaeser PS, Blanpied TA (2017) Transcellular nanoalignment of synaptic function. Neuron 96:680-696.

Boeynaems S, Bogaert E, Kovacs D, Konijnenberg A, Timmerman E, Volkov A, Guharoy M, De Decker M, Jaspers T, Ryan VH, Janke AM, Baatsen P, Vercruysse T, Kolaitis RM, Daelemans D, Taylor JP, Kedersha N, Anderson P, Impens F, Sobott F, et al. (2017) Phase separation of C9orf72 dipeptide repeats perturbs stress granule dynamics. Mol Cell 65:1044-1055.e1045.

Bosch M, Castro J, Saneyoshi T, Matsuno H, Sur M, Hayashi Y (2014) Structural and molecular remodeling of dendritic spine substructures during long-term potentiation. Neuron 82:444-459.

Bosco DA, Lemay N, Ko HK, Zhou H, Burke C, Kwiatkowski TJ Jr, Sapp P, McKenna-Yasek D, Brown RH Jr, Hayward LJ (2010) Mutant FUS proteins that cause amyotrophic lateral sclerosis incorporate into stress granules. Hum Mol Genet 19:4160-4175.

Brangwynne CP, Eckmann CR, Courson DS, Rybarska A, Hoege C, Gharakhani J, Julicher F, Hyman AA (2009) Germline P granules are liquid droplets that localize by controlled dissolution/condensation. Science 324:1729-1732.

Cai Q, Zeng M, Wu X, Wu H, Zhan Y, Tian R, Zhang M (2020) CaMKII $\alpha$ driven, phosphatase-checked postsynaptic plasticity via phase separation. Cell Res Advance online publication. Retrieved Nov 24, 2020. doi: 10.1038/s41422-020-00439-9.

Chen X, Wu X, Wu H, Zhang M (2020) Phase separation at the synapse. Nat Neurosci 23:301-310.

Chen Y, Cohen TJ (2019) Aggregation of the nucleic acid-binding protein TDP-43 occurs via distinct routes that are coordinated with stress granule formation. J Biol Chem 294:3696-3706.

Christie SB, Akins MR, Schwob JE, Fallon JR (2009) The FXG: a presynaptic fragile $\mathrm{X}$ granule expressed in a subset of developing brain circuits. J Neurosci 29:1514-1524.

Conicella AE, Zerze GH, Mittal J, Fawzi NL (2016) ALS mutations disrupt phase separation mediated by alpha-helical structure in the TDP-43 lowcomplexity C-terminal domain. Structure 24:1537-1549.

Conicella AE, Dignon GL, Zerze GH, Schmidt HB, D’Ordine AM, Kim YC, Rohatgi R, Ayala YM, Mittal J, Fawzi NL (2020) TDP-43 alpha-helical structure tunes liquid-liquid phase separation and function. Proc Natl Acad Sci USA 117:5883-5894.

Cougot N, Bhattacharyya SN, Tapia-Arancibia L, Bordonne R, Filipowicz W, Bertrand E, Rage F (2008) Dendrites of mammalian neurons contain specialized P-body-like structures that respond to neuronal activation. J Neurosci 28:13793-13804.

Dao TP, Kolaitis RM, Kim HJ, O’Donovan K, Martyniak B, Colicino E, Hehnly H, Taylor JP, Castaneda CA (2018) Ubiquitin modulates liquidliquid phase separation of UBQLN2 via disruption of multivalent interactions. Mol Cell 69:965-978.e966.

Dewey CM, Cenik B, Sephton CF, Dries DR, Mayer P 3rd, Good SK, Johnson BA, Herz J, Yu G (2011) TDP-43 is directed to stress granules by sorbitol, a novel physiological osmotic and oxidative stressor. Mol Cell Biol 31:1098-1108.

Duan Y, Du A, Gu J, Duan G, Wang C, Gui X, Ma Z, Qian B, Deng X, Zhang K, Sun L, Tian K, Zhang Y, Jiang H, Liu C, Fang Y (2019) PARylation regulates stress granule dynamics, phase separation, and neurotoxicity of disease-related RNA-binding proteins. Cell Res 29:233-247.

Elden AC, Kim HJ, Hart MP, Chen-Plotkin AS, Johnson BS, Fang X, Armakola M, Geser F, Greene R, Lu MM, Padmanabhan A, Clay-Falcone D, McCluskey L, Elman L, Juhr D, Gruber PJ, Rüb U, Auburger G, Trojanowski JQ, Lee VM, et al. (2010) Ataxin-2 intermediate-length polyglutamine expansions are associated with increased risk for ALS. Nature 466:1069-1075.

Feng Z, Chen X, Wu X, Zhang M (2019) Formation of biological condensates via phase separation: characteristics, analytical methods, and physiological implications. J Biol Chem 294:14823-14835.

Fernandes N, Eshleman N, Buchan JR (2018) Stress granules and ALS: a case of causation or correlation? Adv Neurobiol 20:173-212.

Fernandes N, Nero L, Lyons SM, Ivanov P, Mittelmeier TM, Bolger TA, Buchan JR (2020) Stress granule assembly can facilitate but is not required for TDP-43 cytoplasmic aggregation. Biomolecules 10:1367.

Fioriti L, Myers C, Huang YY, Li X, Stephan JS, Trifilieff P, Colnaghi L, Kosmidis S, Drisaldi B, Pavlopoulos E, Kandel ER (2015) The persistence of hippocampal-based memory requires protein synthesis mediated by the prion-like protein CPEB3. Neuron 86:1433-1448.

Ford L, Ling E, Kandel ER, Fioriti L (2019) CPEB3 inhibits translation of mRNA targets by localizing them to P bodies. Proc Natl Acad Sci USA 116:18078-18087.

Gasset-Rosa F, Lu S, Yu H, Chen C, Melamed Z, Guo L, Shorter J, Da Cruz S, Cleveland DW (2019) Cytoplasmic TDP-43 de-mixing independent of stress granules drives inhibition of nuclear import, loss of nuclear TDP43, and cell death. Neuron 102:339-357.e337.

Goncalves J, Bartol TM, Camus C, Levet F, Menegolla AP, Sejnowski TJ, Sibarita JB, Vivaudou M, Choquet D, Hosy E (2020) Nanoscale co-organization and coactivation of AMPAR, NMDAR, and mGluR at excitatory synapses. Proc Natl Acad Sci USA 117:14503-14511.

Grutzendler J, Kasthuri N, Gan WB (2002) Long-term dendritic spine stability in the adult cortex. Nature 420:812-816.

Gu H, Das Gupta J, Schoenberg DR (1999) The poly(A)-limiting element is a conserved cis-acting sequence that regulates poly(A) tail length on nuclear pre-mRNAs. Proc Natl Acad Sci USA 96:8943-8948.

Guo L, Kim HJ, Wang H, Monaghan J, Freyermuth F, Sung JC, O’Donovan K, Fare CM, Diaz Z, Singh N, Zhang ZC, Coughlin M, Sweeny EA, DeSantis ME, Jackrel ME, Rodell CB, Burdick JA, King OD, Gitler AD, Lagier-Tourenne C, et al. (2018) Nuclear-import receptors reverse aberrant phase transitions of RNA-binding proteins with prion-like domains. Cell 173:677-692.e620.

Hafner AS, Donlin-Asp PG, Leitch B, Herzog E, Schuman EM (2019) Local protein synthesis is a ubiquitous feature of neuronal pre- and postsynaptic compartments. Science 364:eaau3644.

Han TW, Kato M, Xie S, Wu LC, Mirzaei H, Pei J, Chen M, Xie Y, Allen J, Xiao G, McKnight SL (2012) Cell-free formation of RNA granules: bound RNAs identify features and components of cellular assemblies. Cell 149:768-779.

Harrison AF, Shorter J (2017) RNA-binding proteins with prion-like domains in health and disease. Biochem J 474:1417-1438.

Hayashi MK, Tang C, Verpelli C, Narayanan R, Stearns MH, Xu RM, Li H, Sala C, Hayashi Y (2009) The postsynaptic density proteins Homer and Shank form a polymeric network structure. Cell 137:159-171.

Hnisz D, Shrinivas K, Young RA, Chakraborty AK, Sharp PA (2017) A phase separation model for transcriptional control. Cell 169:13-23. 
Hosokawa T, Liu P-W, Cai Q, Ferreira JS, Levet F, Butler C, Sibarita JB, Choquet D, Groc L, Hosy E, Zhang M, Hayashi Y (2021) Subsynaptic segregation of glutamate receptors by CaMKII-mediated phase separation. Nat Neurosci, in press.

Hsueh YP, Sheng M (1999) Requirement of N-terminal cysteines of PSD-95 for PSD-95 multimerization and ternary complex formation, but not for binding to potassium channel Kv1.4. J Biol Chem 274:532-536.

Huang YS, Carson JH, Barbarese E, Richter JD (2003) Facilitation of dendritic mRNA transport by CPEB. Genes Dev 17:638-653.

Huang YS, Kan MC, Lin CL, Richter JD (2006) CPEB3 and CPEB4 in neurons: analysis of RNA-binding specificity and translational control of AMPA receptor GluR2 mRNA. EMBO J 25:4865-4876.

Hyman AA, Weber CA, Julicher F (2014) Liquid-liquid phase separation in biology. Annu Rev Cell Dev Biol 30:39-58.

Isshiki M, Tanaka S, Kuriu T, Tabuchi K, Takumi T, Okabe S (2014) Enhanced synapse remodelling as a common phenotype in mouse models of autism. Nat Commun 5:4742.

Ivanov P, Kedersha N, Anderson P (2019) Stress granules and processing bodies in translational control. Cold Spring Harb Perspect Biol 11: a032813.

Jaud M, Philippe C, Di Bella D, Tang W, Pyronnet S, Laurell H, Mazzolini L, Rouault-Pierre K, Touriol C (2020) Translational regulations in response to endoplasmic reticulum stress in cancers. Cells 9:540.

Jin P, Warren ST (2003) New insights into fragile X syndrome: from molecules to neurobehaviors. Trends Biochem Sci 28:152-158.

Johnson BS, Snead D, Lee JJ, McCaffery JM, Shorter J, Gitler AD (2009) TDP-43 is intrinsically aggregation-prone, and amyotrophic lateral sclerosis-linked mutations accelerate aggregation and increase toxicity. J Biol Chem 284:20329-20339.

Jung H, Yoon BC, Holt CE (2012) Axonal mRNA localization and local protein synthesis in nervous system assembly, maintenance and repair. Nat Rev Neurosci 13:308-324.

Kanai Y, Dohmae N, Hirokawa N (2004) Kinesin transports RNA: isolation and characterization of an RNA-transporting granule. Neuron 43:513525

Kato M, Han TW, Xie S, Shi K, Du X, Wu LC, Mirzaei H, Goldsmith EJ, Longgood J, Pei J, Grishin NV, Frantz DE, Schneider JW, Chen S, Li L, Sawaya MR, Eisenberg D, Tycko R, McKnight SL (2012) Cell-free formation of RNA granules: low complexity sequence domains form dynamic fibers within hydrogels. Cell 149:753-767.

Kiebler MA, Bassell GJ (2006) Neuronal RNA granules: movers and makers. Neuron 51:685-690.

Kim HJ, Kim NC, Wang YD, Scarborough EA, Moore J, Diaz Z, MacLea KS, Freibaum B, Li S, Molliex A, Kanagaraj AP, Carter R, Boylan KB, Wojtas AM, Rademakers R, Pinkus JL, Greenberg SA, Trojanowski JQ, Traynor BJ, Smith BN, et al. (2013) Mutations in prion-like domains in hnRNPA2B1 and hnRNPA1 cause multisystem proteinopathy and ALS. Nature 495:467-473.

Kim HJ, Raphael AR, LaDow ES, McGurk L, Weber RA, Trojanowski JQ, Lee VM, Finkbeiner S, Gitler AD, Bonini NM (2014) Therapeutic modulation of eIF2alpha phosphorylation rescues TDP-43 toxicity in amyotrophic lateral sclerosis disease models. Nat Genet 46:152-160.

Kiskinis E, Sandoe J, Williams LA, Boulting GL, Moccia R, Wainger BJ, Han S, Peng T, Thams S, Mikkilineni S, Mellin C, Merkle FT, DavisDusenbery BN, Ziller M, Oakley D, Ichida J, Di Costanzo S, Atwater N, Maeder ML, Goodwin MJ, et al. (2014) Pathways disrupted in human ALS motor neurons identified through genetic correction of mutant SOD1. Cell Stem Cell 14:781-795.

Klann E, Dever TE (2004) Biochemical mechanisms for translational regulation in synaptic plasticity. Nat Rev Neurosci 5:931-942.

Knowles RB, Sabry JH, Martone ME, Deerinck TJ, Ellisman MH, Bassell GJ, Kosik KS (1996) Translocation of RNA granules in living neurons. J Neurosci 16:7812-7820.

Kohrmann M, Luo M, Kaether C, DesGroseillers L, Dotti CG, Kiebler MA (1999) Microtubule-dependent recruitment of Staufen-green fluorescent protein into large RNA-containing granules and subsequent dendritic transport in living hippocampal neurons. Mol Biol Cell 10:2945-2953.

Krichevsky AM, Kosik KS (2001) Neuronal RNA granules: a link between RNA localization and stimulation-dependent translation. Neuron 32: 683-696.
Kuriu T, Inoue A, Bito H, Sobue K, Okabe S (2006) Differential control of postsynaptic density scaffolds via actin-dependent and -independent mechanisms. J Neurosci 26:7693-7706.

Kwiatkowski TJ, Bosco DA, Leclerc AL, Tamrazian E, Vanderburg CR, Russ C, Davis A, Gilchrist J, Kasarskis EJ, Munsat T, Valdmanis P, Rouleau GA, Hosler BA, Cortelli P, de Jong PJ, Yoshinaga Y, Haines JL, PericakVance MA, Yan J, Ticozzi N, et al. (2009) Mutations in the FUS/TLS gene on chromosome 16 cause familial amyotrophic lateral sclerosis. Science 323:1205-1208.

Langdon EM, Gladfelter AS (2018) A new lens for RNA localization: liquidliquid phase separation. Annu Rev Microbiol 72:255-271.

Lee KH, Zhang P, Kim HJ, Mitrea DM, Sarkar M, Freibaum BD, Cika J, Coughlin M, Messing J, Molliex A, Maxwell BA, Kim NC, Temirov J, Moore J, Kolaitis RM, Shaw TI, Bai B, Peng J, Kriwacki RW, Taylor JP (2016) C9orf72 dipeptide repeats impair the assembly, dynamics, and function of membrane-less organelles. Cell 167:774-788.e717.

Lee SJ, Escobedo-Lozoya Y, Szatmari EM, Yasuda R (2009) Activation of CaMKII in single dendritic spines during long-term potentiation. Nature 458:299-304.

Li C, Bassell GJ, Sasaki Y (2009) Fragile X mental retardation protein is involved in protein synthesis-dependent collapse of growth cones induced by semaphorin-3A. Front Neural Circuits 3:11.

Li P, Banjade S, Cheng HC, Kim S, Chen B, Guo L, Llaguno M, Hollingsworth JV, King DS, Banani SF, Russo PS, Jiang QX, Nixon BT, Rosen MK (2012) Phase transitions in the assembly of multivalent signalling proteins. Nature 483:336-340.

Lin Y, Protter DS, Rosen MK, Parker R (2015) Formation and maturation of phase-separated liquid droplets by RNA-binding proteins. Mol Cell 60:208-219.

Lin Y, Mori E, Kato M, Xiang S, Wu L, Kwon I, McKnight SL (2016) Toxic PR poly-dipeptides encoded by the C9orf72 repeat expansion target LC domain polymers. Cell 167:789-802.e712

Liu-Yesucevitz L, Bilgutay A, Zhang YJ, Vanderweyde T, Citro A, Mehta T, Zaarur N, McKee A, Bowser R, Sherman M, Petrucelli L, Wolozin B (2010) Tar DNA binding protein-43 (TDP-43) associates with stress granules: analysis of cultured cells and pathological brain tissue. PLoS One 5:e13250.

Luna E, Luk KC (2015) Bent out of shape: $\alpha$-Synuclein misfolding and the convergence of pathogenic pathways in Parkinson's disease. FEBS Lett 589:3749-3759.

Lyles V, Zhao Y, Martin KC (2006) Synapse formation and mRNA localization in cultured Aplysia neurons. Neuron 49:349-356.

Mackenzie IR, Neumann M (2016) Molecular neuropathology of frontotemporal dementia: insights into disease mechanisms from postmortem studies. J Neurochem 138: 54-70

Mackenzie IR, Nicholson AM, Sarkar M, Messing J, Purice MD, Pottier C, Annu K, Baker M, Perkerson RB, Kurti A, Matchett BJ, Mittag T, Temirov J, Hsiung GY, Krieger C, Murray ME, Kato M, Fryer JD, Petrucelli L, Zinman L, et al. (2017) TIA1 mutations in amyotrophic lateral sclerosis and frontotemporal dementia promote phase separation and alter stress granule dynamics. Neuron 95:808-816.e809.

Maharana S, Wang J, Papadopoulos DK, Richter D, Pozniakovsky A, Poser I, Bickle M, Rizk S, Guillen-Boixet J, Franzmann TM, Jahnel M, Marrone L, Chang YT, Sterneckert J, Tomancak P, Hyman AA, Alberti S (2018) RNA buffers the phase separation behavior of prion-like RNA binding proteins. Science 360:918-921.

Mallardo M, Deitinghoff A, Muller J, Goetze B, Macchi P, Peters C, Kiebler MA (2003) Isolation and characterization of Staufen-containing ribonucleoprotein particles from rat brain. Proc Natl Acad Sci USA 100:21002105.

Mann JR, Gleixner AM, Mauna JC, Gomes E, DeChellis-Marks MR, Needham PG, Copley KE, Hurtle B, Portz B, Pyles NJ, Guo L, Calder CB, Wills ZP, Pandey UB, Kofler JK, Brodsky JL, Thathiah A, Shorter J, Donnelly CJ (2019) RNA binding antagonizes neurotoxic phase transitions of TDP-43. Neuron 102:321-338.e328.

Martin KC (2004) Local protein synthesis during axon guidance and synaptic plasticity. Curr Opin Neurobiol 14:305-310.

Martin KC, Ephrussi A (2009) mRNA localization: gene expression in the spatial dimension. Cell 136:719-730.

McGurk L, Lee VM, Trojanowksi JQ, Van Deerlin VM, Lee EB, Bonini NM (2014) Poly-A binding protein-1 localization to a subset of TDP-43 inclusions in amyotrophic lateral sclerosis occurs more frequently in patients 
harboring an expansion in C9orf72. J Neuropathol Exp Neurol 73:837845.

McGurk L, Gomes E, Guo L, Shorter J, Bonini N (2018a) Poly(ADP-ribose) engages the TDP-43 nuclear-localization sequence to regulate granulo-filamentous aggregation. Biochemistry 57:6923-6926.

McGurk L, Gomes E, Guo L, Mojsilovic-Petrovic J, Tran V, Kalb RG, Shorter J, Bonini NM (2018b) Poly(ADP-ribose) prevents pathological phase separation of TDP-43 by promoting liquid demixing and stress granule localization. Mol Cell 71:703-717.e709.

McGurk L, Mojsilovic-Petrovic J, Van Deerlin VM, Shorter J, Kalb RG, Lee VM, Trojanowski JQ, Lee EB, Bonini NM (2018c) Nuclear poly(ADPribose) activity is a therapeutic target in amyotrophic lateral sclerosis. Acta Neuropathol Commun 6:84-95.

Merkurjev D, Hong WT, Iida K, Oomoto I, Goldie BJ, Yamaguti H, Ohara T, Kawaguchi SY, Hirano T, Martin KC, Pellegrini M, Wang DO (2018) Synaptic N(6)-methyladenosine (m(6)A) epitranscriptome reveals functional partitioning of localized transcripts. Nat Neurosci 21:1004-1014.

Milovanovic D, Wu Y, Bian X, De Camilli P (2018) A liquid phase of synapsin and lipid vesicles. Science 361:604-607.

Molliex A, Temirov J, Lee J, Coughlin M, Kanagaraj AP, Kim HJ, Mittag T, Taylor JP (2015) Phase separation by low complexity domains promotes stress granule assembly and drives pathological fibrillization. Cell 163:123-133.

Montibeller L, de Belleroche J (2018) Amyotrophic lateral sclerosis (ALS) and Alzheimer's disease (AD) are characterised by differential activation of ER stress pathways: focus on UPR target genes. Cell Stress Chaperones 23:897-912.

Murakami T, Qamar S, Lin JQ, Schierle GS, Rees E, Miyashita A, Costa AR, Dodd RB, Chan FT, Michel CH, Kronenberg-Versteeg D, Li Y, Yang SP, Wakutani Y, Meadows W, Ferry RR, Dong L, Tartaglia GG, Favrin G, Lin WL, et al. (2015) ALS/FTD mutation-induced phase transition of FUS liquid droplets and reversible hydrogels into irreversible hydrogels impairs RNP granule function. Neuron 88:678-690.

Murthy AC, Dignon GL, Kan Y, Zerze GH, Parekh SH, Mittal J, Fawzi NL (2019) Molecular interactions underlying liquid-liquid phase separation of the FUS low-complexity domain. Nat Struct Mol Biol 26:637-648.

Neumann M, Sampathu DM, Kwong LK, Truax AC, Micsenyi MC, Chou TT, Bruce J, Schuck T, Grossman M, Clark CM, McCluskey LF, Miller BL, Masliah E, Mackenzie IR, Feldman H, Feiden W, Kretzschmar HA, Trojanowski JQ, Lee VM (2006) Ubiquitinated TDP-43 in frontotemporal lobar degeneration and amyotrophic lateral sclerosis. Science 314:130-133.

Nicoll RA, Tomita S, Bredt DS (2006) Auxiliary subunits assist AMPA-type glutamate receptors. Science 311:1253-1256.

Nimchinsky EA, Oberlander AM, Svoboda K (2001) Abnormal development of dendritic spines in FMR1 knock-out mice. J Neurosci 21:5139-5146.

Parvin S, Takeda R, Sugiura Y, Neyazaki M, Nogi T, Sasaki Y (2019) Fragile $\mathrm{X}$ mental retardation protein regulates accumulation of the active zone protein Munc18-1 in presynapses via local translation in axons during synaptogenesis. Neurosci Res 146:36-47.

Patel A, Lee HO, Jawerth L, Maharana S, Jahnel M, Hein MY, Stoynov S, Mahamid J, Saha S, Franzmann TM, Pozniakovski A, Poser I, Maghelli N, Royer LA, Weigert M, Myers EW, Grill S, Drechsel D, Hyman AA, Alberti S (2015) A liquid-to-solid phase transition of the ALS protein FUS accelerated by disease mutation. Cell 162:1066-1077.

Quiroz FG, Fiore VF, Levorse J, Polak L, Wong E, Pasolli HA, Fuchs E (2020) Liquid-liquid phase separation drives skin barrier formation. Science 367:eaax 9554 .

Richter JD, Lorenz LJ (2002) Selective translation of mRNAs at synapses. Curr Opin Neurobiol 12:300-304.

Ries RJ, Zaccara S, Klein P, Olarerin-George A, Namkoong S, Pickering BF, Patil DP, Kwak H, Lee JH, Jaffrey SR (2019) m(6)A enhances the phase separation potential of mRNA. Nature 571:424-428.

Ryan VH, Dignon GL, Zerze GH, Chabata CV, Silva R, Conicella AE, Amaya J, Burke KA, Mittal J, Fawzi NL (2018) Mechanistic view of hnRNPA2 low-complexity domain structure, interactions, and phase separation altered by mutation and arginine methylation. Mol Cell 69:465-479.e467.
Scheefhals N, MacGillavry HD (2018) Functional organization of postsynaptic glutamate receptors. Mol Cell Neurosci 91:82-94.

Schikorski T, Stevens CF (1997) Quantitative ultrastructural analysis of hippocampal excitatory synapses. J Neurosci 17:5858-5867.

Sharma K, Fong DK, Craig AM (2006) Postsynaptic protein mobility in dendritic spines: long-term regulation by synaptic NMDA receptor activation. Mol Cell Neurosci 31:702-712.

Sheng M, Hoogenraad CC (2007) The postsynaptic architecture of excitatory synapses: a more quantitative view. Annu Rev Biochem 76:823-847.

Sreedharan J, Blair IP, Tripathi VB, Hu X, Vance C, Rogelj B, Ackerley S, Durnall JC, Williams KL, Buratti E, Baralle F, de Belleroche J, Mitchell JD, Leigh PN, Al-Chalabi A, Miller CC, Nicholson G, Shaw CE (2008) TDP-43 mutations in familial and sporadic amyotrophic lateral sclerosis. Science 319:1668-1672.

Sun Z, Diaz Z, Fang X, Hart MP, Chesi A, Shorter J, Gitler AD (2011) Molecular determinants and genetic modifiers of aggregation and toxicity for the ALS disease protein FUS/TLS. PLoS Biol 9:e1000614.

Tang AH, Chen H, Li TP, Metzbower SR, MacGillavry HD, Blanpied TA (2016) A trans-synaptic nanocolumn aligns neurotransmitter release to receptors. Nature 536:210-214.

Tao CL, Liu YT, Sun R, Zhang B, Qi L, Shivakoti S, Tian CL, Zhang P, Lau PM, Zhou ZH, Bi GQ (2018) Differentiation and characterization of excitatory and inhibitory synapses by cryo-electron tomography and correlative microscopy. J Neurosci 38:1493-1510.

Taylor JP, Brown RH Jr, Cleveland DW (2016) Decoding ALS: from genes to mechanism. Nature 539:197-206.

Till SM, Li HL, Miniaci MC, Kandel ER, Choi YB (2011) A presynaptic role for FMRP during protein synthesis-dependent long-term plasticity in Aplysia. Learn Mem 18:39-48.

Tsang B, Arsenault J, Vernon RM, Lin H, Sonenberg N, Wang LY, Bah A, Forman-Kay JD (2019) Phosphoregulated FMRP phase separation models activity-dependent translation through bidirectional control of mRNA granule formation. Proc Natl Acad Sci USA 116:42184227.

Valtschanoff JG, Weinberg RJ (2001) Laminar organization of the NMDA receptor complex within the postsynaptic density. J Neurosci 21:12111217.

Van Treeck B, Parker R (2018) Emerging roles for intermolecular RNA-RNA interactions in RNP assemblies. Cell 174:791-802.

Vance C, Rogelj B, Hortobágyi T, De Vos KJ, Nishimura AL, Sreedharan J, Hu X, Smith B, Ruddy D, Wright P, Ganesalingam J, Williams KL, Tripathi V, Al-Saraj S, Al-Chalabi A, Leigh PN, Blair IP, Nicholson G, de Belleroche J, Gallo JM, et al. (2009) Mutations in FUS, an RNA processing protein, cause familial amyotrophic lateral sclerosis type 6. Science 323:1208-1211.

Vogels T, Leuzy A, Cicognola C, Ashton NJ, Smolek T, Novak M, Blennow K, Zetterberg H, Hromadka T, Zilka N, Scholl M (2020) Propagation of tau pathology: integrating insights from postmortem and in vivo studies. Biol Psychiatry 87:808-818.

Wang J, Choi JM, Holehouse AS, Lee HO, Zhang X, Jahnel M, Maharana S, Lemaitre R, Pozniakovsky A, Drechsel D, Poser I, Pappu RV, Alberti S, Hyman AA (2018) A molecular grammar governing the driving forces for phase separation of prion-like RNA binding proteins. Cell 174:688699.e616.

Wang DO, Kim SM, Zhao Y, Hwang H, Miura SK, Sossin WS, Martin KC (2009) Synapse- and stimulus-specific local translation during long-term neuronal plasticity. Science 324:1536-1540.

Wong HH, Lin JQ, Strohl F, Roque CG, Cioni JM, Cagnetta R, TurnerBridger B, Laine RF, Harris WA, Kaminski CF, Holt CE (2017) RNA docking and local translation regulate site-specific axon remodeling in vivo. Neuron 95:852-868.e858

Wu X, Cai Q, Shen Z, Chen X, Zeng M, Du S, Zhang M (2019) RIM and RIM-BP form presynaptic active-zone-like condensates via phase separation. Mol Cell 73:971-984.e975.

Wu X, Ganzella M, Zhou J, Zhu S, Jahn R, Zhang M (2020) Vesicle tethering on the surface of phase-separated active zone condensates. Mol Cell Advance online publication. Retrieved Nov 9, 2020. doi: 10.1016/j. molcel.2020.10.029.

Xiang S, Kato M, Wu LC, Lin Y, Ding M, Zhang Y, Yu Y, McKnight SL (2015) The LC domain of hnRNPA2 adopts similar conformations in 
hydrogel polymers, liquid-like droplets, and nuclei. Cell 163:829839.

Yang G, Pan F, Gan WB (2009) Stably maintained dendritic spines are associated with lifelong memories. Nature 462:920-924.

Zalfa F, Achsel T, Bagni C (2006) mRNPs, polysomes or granules: FMRP in neuronal protein synthesis. Curr Opin Neurobiol 16:265-269.

Zbinden A, Perez-Berlanga M, De Rossi P, Polymenidou M (2020) Phase separation and neurodegenerative diseases: a disturbance in the force. Dev Cell 55:45-68.

Zeng M, Shang Y, Araki Y, Guo T, Huganir RL, Zhang M (2016) Phase transition in postsynaptic densities underlies formation of synaptic complexes and synaptic plasticity. Cell 166:1163-1175. e1112.
Zeng M, Chen X, Guan D, Xu J, Wu H, Tong P, Zhang M (2018) Reconstituted postsynaptic density as a molecular platform for understanding synapse formation and plasticity. Cell 174:1172-1187. e1116.

Zeng M, Diaz-Alonso J, Ye F, Chen X, Xu J, Ji Z, Nicoll RA, Zhang M (2019) Phase separation-mediated TARP/MAGUK complex condensation and AMPA receptor synaptic transmission. Neuron 104:529543.e526.

Zhang K, Daigle JG, Cunningham KM, Coyne AN, Ruan K, Grima JC, Bowen KE, Wadhwa H, Yang P, Rigo F, Taylor JP, Gitler AD, Rothstein JD, Lloyd TE (2018) Stress granule assembly disrupts nucleocytoplasmic transport. Cell 173:958-971.e917. 